\title{
Contraceptive use in women with hypertension and diabetes: cross-sectional study in northwest Ethiopia
}

\section{Tensae Tadesse Mekonnen' Solomon Meseret Woldeyohannes ${ }^{2}$ Tegbar Yigzaw ${ }^{3}$}

'Department of Midwifery, Tseda Health Science College, ${ }^{2}$ Department of Epidemiology and Biostatistics, Institute of Public Health, University of Gondar, Gondar, ${ }^{3}$ Jhpiego-Ethiopia, Addis Ababa, Ethiopia
Correspondence:Tensae Tadesse Mekonnen

Department of Midwifery, Tseda Health Science College, PO Box 102, Gondar, Ethiopia

Tel/fax +25I 5 8I I | 622 I

Email almaztade@gmail.com
This article was published in the following Dove Press journal:

International Journal of Women's Health

II December 2015

Number of times this article has been viewed

Purpose: Women with diabetes and hypertension are at increased risk of pregnancy complications, including those from surgical delivery and their offspring are at risk for congenital anomalies. Thus, diabetic and hypertensive women of reproductive age are advised to use valid contraceptive methods for reducing unwanted pregnancy and its complications. However, contraceptive use among these segments of the population had not been previously assessed in Ethiopia. Hence, the aim of this study was to assess contraceptive use and associated factors among diabetic and hypertensive women of reproductive age on chronic follow-up care at University of Gondar and Felege Hiwot Hospitals.

Methods: Hospital-based cross-sectional study was conducted from April to May 2012 among diabetic and hypertensive women on follow-up at the chronic illness care center. The sample size calculated was 403. Structured and pretested questionnaire was used for data collection. Data were collected using interview supplemented by chart review. The data were entered using EPI info Version 2000 and analyzed using SPSS Version 16. Frequencies, proportion, and summary statistics were used to describe the study population in relation to relevant variables. Both bivariate and multivariate analyses were run to see the association of each independent variable with contraceptive practice.

Results: A total of 392 married women on chronic follow-up care were interviewed making the response rate of $93.3 \%$. The contraceptive prevalence rate was found to be $53.8 \%$. Factors such as age 25-34 years (adjusted odds ratio, AOR [95\% confidence interval, $\mathrm{CI}]=3.60$ [1.05-12.36]), (AOR $[95 \% \mathrm{CI}]=2.29[1.15-4.53])$, having middle- and high-level incomes $(\mathrm{AOR}[95 \% \mathrm{CI}]=$ 2.12 [1.19-3.77]), (AOR [95\% CI] =5.03 [2.19-11.54]), receiving provider counseling (AOR $[95 \% \mathrm{CI}]=9.02[4.40-18.49])$, and controlled disease condition $(\mathrm{AOR}[95 \% \mathrm{CI}]=4.13[2.35-$ 7.28]) were significantly associated with contraceptive practice.

Conclusion: The contraceptive utilization of women on diabetes and hypertension follow-up care was found to be low. Hence, strengthening counseling and education about family planning and controlling their medical conditions would help increase the contraceptive uptake of women on chronic follow-up.

Keywords: family planning, chronic disease, pregnancy

\section{Introduction}

Chronic diseases, such as heart disease, hypertension, diabetes, cancers, and chronic respiratory diseases, are by far the leading cause of mortality and morbidity in the world. ${ }^{1}$ From the 58 million deaths that occurred in 2005, 35 million were from chronic diseases, ${ }^{2}$ and among these, 18 million were women. ${ }^{3}$ Women are uniquely affected by chronic disease. In the developing world, the effect of chronic diseases on women is even more pronounced. Women comprise $60 \%$ of the world's poor, and poverty worsens the chances of survival from chronic disease. ${ }^{4}$ 
Globally, there are 300 million people who have diabetes, and approximately half of these are women. ${ }^{4} \mathrm{~A}$ study that was conducted in Addis Ababa showed that from a total of 229 diabetic clients, $63.85 \%$ were females. ${ }^{5}$ Hypertension is also an important cause of mortality and morbidity in reproductive age women. ${ }^{6}$ Although younger, premenopausal women have lower blood pressures (BPs) than the age-matched men population, BP rises with age, and the prevalence of hypertension is higher in older women. ${ }^{7}$ In 2006 , the prevalence of hypertension in reproductive age US women was $6.9 \%{ }^{8}$ A population-based study that was conducted in Addis Ababa showed that the prevalence of hypertension in adult females was found to be $29 \%$. $^{9}$

Women with diabetes and hypertension are at increased risk of pregnancy-related complications, which includes spontaneous abortion, preterm labor, hypertensive disorders, and delivery by cesarean section. ${ }^{10}$ Existing population-based studies demonstrated increased congenital abnormalities and prenatal mortality in diabetic mothers as compared to the nondiabetic population. ${ }^{11,12}$ Clinical and experimental evidence indicate that the increased risk of congenital malformation and spontaneous abortion in pregnancies complicated by diabetes is linked to disturbance in maternal metabolism around the time of conception and during the period of organogenesis. ${ }^{13}$ Unfortunately, unplanned pregnancies occur in twothirds of women with diabetes, leading to persistent excess malformation in their infants. ${ }^{14}$ There are no contraceptive methods that are specifically contraindicated for women with diabetes. ${ }^{13}$ Thus, the selection of a method for an individual patient should be made by a provider who is familiar with contraceptive prescribing practices using the same guidelines that are relevant to a woman without diabetes. Because unexpected failure of contraception can lead to increased risk of congenital malformation and spontaneous abortion in pregnancies complicated by diabetes, the focus should be on methods with verified high degree of effectiveness. ${ }^{15}$

Although research and educational efforts addressing contraceptive use in women with medical problems are limited, pregnancy in women with medical disease in many instances exposes both the woman and her offspring to definite morbidity and possible mortality. ${ }^{14}$ Women with a medical disease should be offered the most effective methods of contraception that also safeguard their existing health status. ${ }^{15}$

The lack of contraceptive use in this high-risk group population is related to sociodemographic and other factors related to pregnancy. ${ }^{13}$ Approximately half of all pregnancies in USA are unintended and nearly two-thirds of pregnancies in women with diabetes are unplanned. ${ }^{16}$
Hence, diabetes and hypertension are diseases with severe complications. The problems are even more pronounced among reproductive women than in nonreproductive women. Women with diabetes and hypertension are at increased risk of pregnancy complications, including those from surgical delivery, and their offspring are at risk of congenital anomalies. Thus, diabetic and hypertensive women of reproductive age must use valid contraceptive methods for reducing unwanted pregnancy and its complications. Effective family planning used in conjunction with hypertension and glucose management may reduce the risk to both the mother and the fetus. In spite of family planning benefits to these categories of the population, practice of using contraceptive among these segments of the population in Ethiopia was not previously assessed. Therefore, this study was conducted with the purpose of assessing contraceptive practice by diabetic and hypertensive married women of reproductive age group on follow-up at the chronic illness care center, with the hope of bringing information to support and guide further development and accomplishment of specific intervention program targeted to women of reproductive age group with diabetes and hypertension. Besides, it could serve as a baseline data for planning future studies.

\section{Materials and methods}

Institution-based cross-sectional study was conducted from April to May, 2012, at the University of Gondar Referral Hospital and Felege Hiwot Referral Hospital. These two hospitals are the largest public hospitals in the Amhara National Regional State. A total of 4,096 diabetic and 2,100 hypertensive clients were having regular follow-up at the two hospitals. Among these, 2,795 (1,995 diabetic and 800 hypertensive) were women. All women who fulfilled the inclusion criteria (married women of reproductive age, ie, 15-49 years, who were not pregnant and infertile at the time of the study) and who came for follow-up visit during the data collection period were enrolled. These women came because they seek care, hence, the study has nothing to do with absence or presence of women during the study period and this could help in minimizing the selection bias.

Sample size was determined using the formula for estimating a single population proportion. ${ }^{17}$ The following assumptions were made while calculating the sample size. A 95\% probability of obtaining the population proportion of women who practice contraceptive within 5\% margin of error was assumed to be $50 \%$ as there were no studies done in Ethiopia about contraceptive practice and associated 
factors among diabetic and hypertensive women. Following the assumptions and using the Statistical Package Epi_Info Version 2000 (Centers for Disease Control and Prevention, Atlanta, GA, USA), the required size was 385 married women in the reproductive age group. Expecting a 5\% nonresponse rate, the final sample size was calculated to be 403 .

Nurses collected the data via interview using structured questionnaire. To assure data quality, a number of precautions were taken. The questionnaire was prepared in English, translated to Amharic, and then translated back to English, to check for consistency. Training was given for the data collectors. Before the actual data collection, pretest was done on 21 women in the follow-up care and appropriate modifications were made on the questionnaire after analyzing the pretest result. The supervisors and the principal investigator made frequent checks on the data collection process to ensure the completeness and consistency of the gathered information.

Data were collected on women's age, place of residence, educational status, occupation of mother, monthly income, media exposure, duration of follow-up, BP or glucose level, number of comorbidities and provider counseling, and number of living children and contraceptive practice. Operational definitions were performed on the following variables.

Controlled hypertension: If a woman had maintained the average BP reading $<140 / 90 \mathrm{mmHg}$ at the time of data collection irrespective of measurements at other times. However, readings $\geq 140 / 90 \mathrm{mmHg}$ is referred as uncontrolled hypertension.

Controlled diabetes: If a woman had maintained mean fasting blood sugar $<130 \mathrm{mg} / \mathrm{dL}$ for the last three consecutive visits.

Contraceptive practice: Usage of one of hormonal, barrier, or sterilization method of contraceptives. In this study, contraceptive use refers to if a woman is currently using any one of hormonal, barrier, or sterilization method. Hence, a woman was categorized as current contraceptive user if she used one of the methods, otherwise as a nonuser.

Family monthly income: Low level - if the family monthly income is $<25 \%$ quartile, that is, $<500$ Birr; Middle level - if the family monthly income is between the $25 \%$ and $75 \%$ quartile, 500-2,000 Birr; High level - if the family monthly income is $>75 \%$ quartile, that is, $>2,000$ Birr.

The data were entered and cleaned using EPI info Version 6 statistical software (Centers for Disease Control and Prevention) and exported to SPSS Version 16 statistical packages for analysis. Frequencies, proportion and summary statistics were used to describe the study population in relation to relevant variables. Logistic regression was carried out to see the effect of each independent variable on the dependent variable. $P$-value $<0.05$ was used to declare statistical significance. Odds ratio with $95 \%$ CI was computed to assess the strength of the association.

Ethical clearance was obtained from the Ethical Review Board of Institute of Public Health. Communication with the University of Gondar Hospital and Felege Hiwot Hospital was made through formal letter. After the purpose and objective of the study have been informed, verbal consent was obtained from each study participant. Participants were also informed that participation would be on voluntary basis, and they could withdraw from the study at any time if they were not comfortable about the questionnaire. Participants were also informed that all data obtained from them would be kept confidential by using codes instead of any personal identifiers.

\section{Results}

\section{Sociodemographic and economic characteristics of the respondents}

A total of 392 women responded to the questionnaire, yielding a response rate of $97.3 \%$. One hundred fifty-four (39.3\%) respondents were from the rural areas. The mean age of the respondents was $36 \pm 7.58$ years. Approximately $45 \%$ of the study participants and $33.4 \%$ of their spouses did not have formal education. Most respondents $(87 \%)$ belonged to the Amhara ethnic group and (78.6\%) were followers of Orthodox Christianity. Furthermore, 53.1\% (208) of women were housewives, 53.3\% (209) had middle-level family income, and $83.8 \%$ (329) possessed radio and/or television (Table 1).

\section{Chronic medical conditions}

Approximately half (49.5\%) and one-third (35.7\%) of the study participants had diabetes mellitus and hypertension, respectively, while the remaining $14.8 \%$ had both. More than eight out of ten women were on follow-up for $>1$ year, and the disease was well controlled in 271 (69.1\%) of the patients. In addition, 100 (25.5\%) women had comorbidity and $68(17.3 \%)$ reported facing pregnancy complication after they developed the disease (Table 2).

\section{Contraceptive practice}

Two hundred seventy-one (69.1\%) women reported that they ever used contraceptive methods. However, only $53.8 \%$ 
Table I Sociodemographic and economic characteristics of the study participants, May 2012

\begin{tabular}{|c|c|c|}
\hline Variables & Frequency & Percentage \\
\hline \multicolumn{3}{|l|}{ Residence } \\
\hline Rural & 154 & 39.3 \\
\hline Urban & 238 & 60.7 \\
\hline \multicolumn{3}{|l|}{ Age, years } \\
\hline$\leq 24$ & 34 & 8.7 \\
\hline $25-34$ & 95 & 24.2 \\
\hline$\geq 35$ & 263 & 67.1 \\
\hline \multicolumn{3}{|l|}{ Ethnicity } \\
\hline Amhara & 343 & 87.5 \\
\hline Tigre & 27 & 6.9 \\
\hline Others & 22 & 5.6 \\
\hline \multicolumn{3}{|l|}{ Religion } \\
\hline Orthodox Christian & 308 & 78.6 \\
\hline Muslim & 70 & 17.9 \\
\hline Protestant & 13 & 3.3 \\
\hline Catholic Christian & 1 & 0.3 \\
\hline \multicolumn{3}{|l|}{ Educational status } \\
\hline Cannot read and write & 129 & 32.9 \\
\hline Read and write & 49 & 12.5 \\
\hline Class I-6 & 33 & 8.4 \\
\hline Class 7-10 & 65 & 16.6 \\
\hline Class $11-12$ & 96 & 24.5 \\
\hline College or university & 20 & 5.1 \\
\hline \multicolumn{3}{|l|}{ Women occupation } \\
\hline Housewife & 208 & 53.1 \\
\hline Merchant & 61 & 15.6 \\
\hline Daily laborer & 27 & 6.9 \\
\hline Government employee & 96 & 24.5 \\
\hline \multicolumn{3}{|l|}{ Husband educational status } \\
\hline Cannot read and write & 45 & 11.5 \\
\hline Read and write & 86 & 21.9 \\
\hline Class I-6 & 34 & 8.7 \\
\hline Class $7-10$ & 57 & 14.5 \\
\hline Class II-12 & 108 & 27.6 \\
\hline College or university & 62 & 15.8 \\
\hline \multicolumn{3}{|l|}{ Husband occupation } \\
\hline Merchant & 104 & 26.5 \\
\hline Government employee & 159 & 40.6 \\
\hline Daily laborer & 56 & 14.3 \\
\hline Farmer & 73 & 18.6 \\
\hline \multicolumn{3}{|l|}{ Family monthly income } \\
\hline Low & 114 & 29.1 \\
\hline Middle & 209 & 53.3 \\
\hline High & 69 & 17.6 \\
\hline \multicolumn{3}{|l|}{ Having TV or radio } \\
\hline Radio & 97 & 24.7 \\
\hline TV & 28 & 7.1 \\
\hline Radio and TV & 204 & 52.0 \\
\hline None & 63 & 16.1 \\
\hline
\end{tabular}

(211) were using modern contraceptive methods during the time of data collection. The frequently used methods were injectable (39.8\%), intrauterine contraceptive device (IUCD) (18\%), pill (16.1\%), and implant (14.2\%). More than half (53.1\%) of the women were using contraceptives for the purpose of limiting births. The most frequently mentioned
Table 2 Chronic medical conditions of the study participants, May 2012

\begin{tabular}{lll}
\hline Variables & Frequency & Percentage \\
\hline Type of disease & & \\
Diabetes & 194 & 49.5 \\
Hypertension & 140 & 35.7 \\
$\quad$ Both & 58 & 14.8 \\
Duration of follow-up & & \\
II years & 68 & 17.3 \\
I-4 years & 178 & 45.4 \\
$>4$ years & 146 & 37.2 \\
Disease controlled & & \\
Yes & 271 & 69.1 \\
No & 121 & 30.9 \\
Comorbidity & & \\
Yes & 100 & 25.5 \\
No & 292 & 74.5 \\
History of pregnancy complication & 17.3 \\
Yes & 68 & 82.7 \\
No & 324 & \\
\hline
\end{tabular}

reasons for not using contraceptive were fear of side effects (12.8\%), desire for children (12.2\%), religious prohibition (11.2\%), husband opposition (11\%), and lack of knowledge about contraceptives $(8.9 \%$; Table 3$)$.

Table 3 Contraceptive practice of the respondents, May 2012

\begin{tabular}{|c|c|c|}
\hline Variable & Frequency & Percentage \\
\hline \multicolumn{3}{|l|}{ Ever use } \\
\hline Yes & 271 & 69.1 \\
\hline No & 121 & 30.9 \\
\hline \multicolumn{3}{|l|}{ Current use } \\
\hline Yes & 211 & 53.8 \\
\hline No & 181 & 46.2 \\
\hline \multicolumn{3}{|l|}{ Contraceptive type currently using } \\
\hline Pills & 34 & 16.1 \\
\hline IUCD & 38 & 18 \\
\hline DMPA & 84 & 39.8 \\
\hline Norplant & 30 & 14.2 \\
\hline Tubal ligation & 16 & 7.6 \\
\hline Emergency pills & 5 & 2.4 \\
\hline Natural method & 4 & 1.8 \\
\hline \multicolumn{3}{|l|}{ Purpose of using } \\
\hline Spacing between children & 99 & 46.9 \\
\hline Limiting the number of children & 112 & 53.1 \\
\hline \multicolumn{3}{|l|}{ Husband approval } \\
\hline Approve & 156 & 39.8 \\
\hline Disapprove & 219 & 55.9 \\
\hline Do not know & 17 & 4.3 \\
\hline \multicolumn{3}{|l|}{ Reasons for nonuse } \\
\hline Fear of side effect & 50 & 12.8 \\
\hline Not aware of contraceptive & 35 & 8.9 \\
\hline Husband opposition & 43 & 11.0 \\
\hline Infrequent sex & 35 & 8.9 \\
\hline Religion prohibition & 44 & 11.2 \\
\hline Desire for children & 48 & 12.2 \\
\hline
\end{tabular}

Abbreviations: IUCD, intrauterine contraceptive device; DMPA, depot medroxyprogesterone acetate. 


\section{Factors associated with contraceptive use}

The impact of selected sociodemographic and other characteristics on contraceptive practice was investigated using both the classic bivariate methods and the multivariate logistic regression technique. Variables found to be significant at $P$-value of 0.2 were included in the multivariate analysis. Finally, age, income, discussion with health worker about contraception, well-controlled disease condition, and having living children were found to be significantly and independently associated with contraceptive practice of women with chronic disease on follow-up care. Accordingly, women belonging to age groups 25-34 years (adjusted odds ratio, AOR [95\% confidence interval, CI] $=3.6(1.1-12.4])$ and $35-39$ years $(\mathrm{AOR}[95 \% \mathrm{CI}]=2.3(1.2-4.5])$ were more likely to use contraceptives as compared to those younger than 25 years. Participants in high- $(\mathrm{AOR}[95 \% \mathrm{CI}]=2.1$ $[1.2-3.8])$ and middle- $(\mathrm{AOR}[95 \% \mathrm{CI}]=5.0[2.2-11.5])$ income groups were more likely to use contraceptive than those in low-level income group.

The number of living children that the women had was also a factor that had influence on contraceptive practice. Women having one to four (AOR [95\% CI] $=7.2$ [2.4-21.9]) and five and more (AOR [95\% CI] $=7.6$ [2.9-19.5]) living children were approximately seven times more likely to use contraceptives than women with no children. Having discussion with health professionals concerning contraceptive issues for women with chronic disease was important because it helped them to practice it. Respondents reporting having discussion concerning contraceptives were approximately nine times more likely to use contraceptive (AOR [95\% CI $=9.0[4.40-18.5] ;$ Table 4).

\section{Discussion}

Contraception in women suffering from chronic diseases is an important question, mainly as it has been proven that pregnancy outcome both for the fetus and for the mother depends on disease condition before conception right to delivery. ${ }^{18}$ Women with chronic medical conditions are of particular concern due to significantly increased risk for pregnancy-related morbidity, mortality, and adverse pregnancy outcomes. This has made planning of future pregnancy mandatory for these patients. ${ }^{18,19}$ In this study, $53.8 \%$ of married women surveyed were using contraceptive methods. Although this figure was higher than contraceptive prevalence rate at national (29\%) and regional state (33.9\%) levels as reported in the 2011 Ethiopian Demographic and Health Survey, ${ }^{20}$ the greater likelihood of risk to the mother and the fetus in this group makes the contraceptive use unacceptably low. Studies done in Michigan, Iran, and Italy reported very high levels of contraceptive use among women with chronic medical conditions, $80 \%, 85 \%$, and $89.3 \%,{ }^{21-23}$ respectively, while a study from Algeria found comparable contraceptive prevalence. ${ }^{24}$

In this study, we found an association between contraceptive use and women's age, income level, presence of children, discussion with health care providers about contraception, and status of disease control. Women $\geq 25$ years of age were more likely to use contraceptive than their younger counterparts. This might be because younger married women have greater desire for more children and, hence, do not use contraceptives. This interpretation is consistent with the finding in this study that the desire for more children was the second most frequent reason for the nonuse of contraceptives. This finding was in line with other studies done in USA and Italy. ${ }^{21,22}$

Women in the middle and higher income groups in this study were more likely to use contraceptives than those who have low income. This finding is consistent with results from the Ethiopian demographic and health survey that reported current use of contraceptives increases with wealth. ${ }^{20}$ This may be due to situational, demographic, and behavioral factors related to economical status that increase the knowledge, motivation, and get necessary support to practice contraceptives. Having higher income has similarly been identified in other studies as having significant association with contraceptive use among women with diabetes who seek preconception care and continuous use of contraception. ${ }^{25,26}$

In this study, "having living children" was strongly associated with the contraceptive practice. This finding is consistent with the pattern in the Ethiopian demographic and health survey, which reported higher contraceptive use among women having one to four living children than those without children..$^{20}$ This is because the main determinant to contraception continuation and type seems to be the size of the family, which is determined by the number of children. It is also considered as one of the major determinants in the developing countries. This result is similar with Algeria's study. ${ }^{24}$

The study demonstrates that women who discussed with health care providers about contraceptive use were approximately nine times more likely to practice contraceptive than those who did not. This is intuitive because discussion increases women's contraceptive knowledge and addresses their concerns, thereby facilitating adoption and continuation of contraceptive use. It is known that when health care providers counsel clients well, it helps them successfully choose and use contraceptives. ${ }^{25}$ 
Table 4 Association of selected sociodemographic and other characteristics with contraceptive practice among women on chronic follow-up care at Gondar University Hospital and Felege Hiwot Hospital, May 2012

\begin{tabular}{|c|c|c|c|c|}
\hline \multirow[t]{2}{*}{ Variable } & \multicolumn{2}{|c|}{ Contraceptive use } & \multirow[t]{2}{*}{ Crude OR $(95 \% \mathrm{Cl})$} & \multirow[t]{2}{*}{ Adjusted OR $(95 \% \mathrm{Cl})$} \\
\hline & Yes & No & & \\
\hline \multicolumn{5}{|l|}{ Age, years } \\
\hline$\leq 24$ & $13(38.2 \%)$ & $21(61.8 \%)$ & 1 & 1 \\
\hline $25-34$ & $56(58.9 \%)$ & 39 (4I.1\%) & $2.3(1.0-5.2)$ & $3.6(1.1-12.4)$ \\
\hline $35-49$ & $142(54.0 \%)$ & $|2|(46.0 \%)$ & $1.9(0.9-3.9)$ & $2.3(1.2-4.5)$ \\
\hline \multicolumn{5}{|l|}{ Resident } \\
\hline Rural & 75 (48.7\%) & 79 (51.3\%) & 1 & \\
\hline Urban & I 36 (57.1\%) & $102(42.9 \%)$ & $1.4(0.9-2.1)$ & \\
\hline \multicolumn{5}{|l|}{ Educational status } \\
\hline Cannot read and write & 65 (50.4\%) & $64(49.6 \%)$ & 1 & \\
\hline Read and write & $32(65.3 \%)$ & $17(34.7 \%)$ & $1.9(0.9-3.7)$ & \\
\hline Class $\leq 10$ & 45 (45.9\%) & $53(54.1 \%)$ & $0.8(0.5-1.4)$ & \\
\hline Class II+ & 69 (59.5\%) & 47 (40.5\%) & $1.4(0.9-2.4)$ & \\
\hline \multicolumn{5}{|l|}{ Occupation } \\
\hline Housewife & $108(51.9 \%)$ & $100(48.1 \%)$ & 1 & \\
\hline Merchant & $35(57.4 \%)$ & $26(42.6 \%)$ & I.3 (0.7-2.2) & \\
\hline Daily Laborer & II (40.7\%) & $16(59.3 \%)$ & $0.6(0.3-1.4)$ & \\
\hline Government employee & 57 (59.4\%) & $39(40.6 \%)$ & $1.4(0.8-2.2)$ & \\
\hline \multicolumn{5}{|l|}{ Having TV/radio } \\
\hline Radio & 49 (50.5\%) & 48 (49.5\%) & $2.4(1.2-4.6)$ & \\
\hline TV & 15 (53.6\%) & $13(46.4 \%)$ & $2.7(1.1-6.7)$ & \\
\hline Both & $128(62.7 \%)$ & 76 (37.3\%) & $3.9(2.1-7.2)$ & \\
\hline None & $19(30.2 \%)$ & 44 (69.8\%) & 1 & \\
\hline \multicolumn{5}{|l|}{ Income } \\
\hline Low & $40(35.1 \%)$ & 74 (64.9\%) & 1 & I \\
\hline Middle & $116(55.5 \%)$ & 93 (44.5\%) & $2.3(1.4,3.7)$ & $2.1(1.2-3.8)$ \\
\hline High & $55(79.7 \%)$ & $14(20.3 \%)$ & $7.3(3.6,14.7)$ & $5.0(2.2-11.5)$ \\
\hline \multicolumn{5}{|l|}{ No of living children } \\
\hline None & I8 (25.4\%) & $53(74.6 \%)$ & 1 & 1 \\
\hline $1-4$ & $158(64.0 \%)$ & $89(36.0 \%)$ & $5.2(2.9,9.5)$ & $7.2(2.4-21.9)$ \\
\hline$>5$ & $35(47.3 \%)$ & 39 (52.7\%) & $2.6(1.3,5.3)$ & $7.6(2.9-19.5)$ \\
\hline \multicolumn{5}{|c|}{ Discussion with health workers } \\
\hline Yes & 91 (89.2\%) & II (I0.8\%) & II.7 (6.0-22.9) & $9.1(4.4-18.5)$ \\
\hline No & $120(41.4 \%)$ & $170(58.6 \%)$ & 1 & 1 \\
\hline \multicolumn{5}{|l|}{ Disease controlled } \\
\hline Yes & I $82(67.2 \%)$ & $89(32.8 \%)$ & $6.5(3.9-10.6)$ & 4.I (2.4-7.4) \\
\hline No & $29(24.0 \%)$ & $92(76.0 \%)$ & 1 & 1 \\
\hline \multicolumn{5}{|l|}{ Duration of follow-up } \\
\hline$<\mid$ years & $4 \mathrm{I}(60.3 \%)$ & 27 (39.7\%) & 1 & \\
\hline $\mathrm{I}-4$ years & 99 (55.6\%) & 79 (44.4\%) & $0.8(0.5-1.5)$ & \\
\hline$>4$ years & 71 (48.6\%) & 75 (5I.4\%) & $0.6(0.4-1.1)$ & \\
\hline \multicolumn{5}{|l|}{ Comorbidities } \\
\hline Yes & $55(55.0 \%)$ & 45 (45.0\%) & I.I (0.7-I.7) & \\
\hline No & $156(53.4 \%)$ & $136(46.6 \%)$ & $\mathrm{I}$ & \\
\hline
\end{tabular}

Abbreviations: $\mathrm{OR}$, odds ratio; $\mathrm{Cl}$, confidence interval.

Regarding disease condition, women whose medical condition is controlled were more likely to practice contraceptives than those who did not. The reason may be those women with better controlled disease did so because they adhere to medical advice and, by extension, are more likely to use contraceptives. It is also possible that women in good health condition are more likely to be sexually active and use contraceptives.

\section{Limitations of the study}

This study could have the following limitations. First, since the study was done only among women on follow-up care, generalization could not be made to all women with hypertension and diabetes who were not at follow-up care at the time of the study. Data regarding treatment adherence, body mass index, husband-wife communications on choice and decisions were not collected, which might have implications 
on the current findings of the study. In addition, the role of mass media on contraceptive practice was not assessed. Finally, there could be a possibility for social desirability of responses.

\section{Conclusion}

Contraceptive utilization of women on diabetes and hypertension follow-up care was found to be low. Women aged 25-34 years, of high and middle level family monthly income groups, having more than five living children, providing counseling and controlling of the disease were found to have positive association with the contraceptive practice. Hence, strengthening counseling, education about family planning, and controlling their medical conditions would help increase the contraceptive uptake of women on chronic follow-up care.

\section{Acknowledgments}

The authors would like to forward our deepest gratitude to the staff of the Institute of Public Health for their material and technical support and to the women who participated in the study.

\section{Author contributions}

All authors made substantial contributions to conception and design, acquisition of data, or analysis and interpretation of data; took part in either drafting the article or revising it critically for important intellectual content; gave final approval of the version to be published; and agree to be accountable for all aspects of the work.

\section{Disclosure}

The authors report no conflicts of interest in this work.

\section{References}

1. Alwan A, MacLean DR, Riley LM, et al. Monitoring and surveillance of chronic non-communicable diseases: progress and capacity in highburden countries. Lancet. 2010;376(9755):1861-1868.

2. World Health Organization. Preventing chronic diseases: a vital investment. Geneva: World Health Organization; 2005. Available from: http:/ www.who.int/chp/chronic_disease_report/en/. Accessed September 17, 2015.

3. World Health Organization. Global status report on noncommunicable diseases 2010. Geneva: World Health Organization; 2010. Available from: http://www.who.int/nmh/publications/ncd_report_full_en.pdf. Accessed September 17, 2015.

4. The NCD Alliance. Noncommunicable diseases: a priority for women's health and development. 2010. Available from: http://www.who.int/ pmnch/topics/maternal/2011_women_ncd_report.pdf.pdf. Accessed September 17, 2015.
5. Feleke Y, Enkuselassie F. An assessment of the health care system for diabetes in Addis Ababa, Ethiopia. Ethiop J Health Dev. 2005;19(3): 203-210.

6. Say L, Chou D, Gemmill A, et al. Global causes of maternal death: a WHO systematic analysis. Lancet Glob Health. 2014;2(6):e323-e333.

7. August $\mathrm{P}$, Oparil S. Acute Long term management of hypertension in non-pregnant women. BMJ. 2012;27(5):145-178.

8. CDC. Preventing and managing chronic disease to improve the health of women and infants; 2010. Available from: http://www.cdc.gov/ reproductivehealth.

9. Tesfaye F, Byass P, Wall S. Population based prevalence of high blood pressure among adults in Addis Ababa: uncovering a silent epidemic. Cardiovasc Disord. 2009;9(39):1471-2261.

10. Casson IF, Clarke CA, Howard CV, McKendrick O, Pennycook S, Pharonah PO. Outcomes of pregnancy in insulin dependent diabetic women:result of a five year population cohort study. BMJ. 1997;315: 275-278.

11. Wahabi HA, Alzeidan RA, Bawazeer GA. Pre conception care for diabetic women for improving maternal and fetal outcomes systemic review. Diabetes Care. 2010;10(63):1471-2393.

12. American Diabetes Association. Preconception care of women with diabetes. Diabetes Care. 2004;27(suppl 1):S76-S78.

13. Rey E, Couturier A. The prognosis of pregnancy in women with chronic hypertension. Am J Obstet Gynecol. 1994;171(2):410-416.

14. Kjos SL. Contraception for women with medical problems. In: Gynecology and Obstetrics CD-ROM. Philadelphia: Lippincott Williams and Wilkins; 2004;1-6:Chapter 14.

15. Institute of Medicine. Weight gain during pregnancy; 2010. Available from: www.iom.edu/Reports/2009/Weight-Gain-DuringPregnancyReexamining-theGuidelines.aspx. Accessed April 2, 2012.

16. Evers IM, de Valk HW, Visser GH. Risk of complications of pregnancy in women with type 1 diabetes: nationwide prospective study in the Netherlands. BMJ. 2004;328(7445):915.

17. Fosgate GT. Practical sample size calculations for surveillance and diagnostic investigations. J Vet Diagn Invest. 2009;21(1):3-14.

18. Nikolov A, Dimitrov A, Kolarov G, Todarova K, Mekhandzhiev T Contraception in women with diabetes mellitus. Akush Ginekol. 2005; 44(5):47-52.

19. Dunlop AL, Jack BW, Bottalico JN, et al. The clinical content of preconception care: women with chronic medical conditions. Am J Obstet Gynecol. 2008;34(2):S310-S327.

20. Central Statistical Agency [Ethiopia] and ICF International. Ethiopia Demographic and Health Survey 2011. Addis Ababa, Ethiopia and Calverton, Maryland, USA: Central Statistical Agency and ICF International; 2012.

21. Cynthia H, Chuang A. Contraceptiveuse by diabetic and obese women. Womens Health Issue. 2005;15(4):167-173.

22. Mazaheri E, Mostafazadeh F, Karimollahi M. Pattern of contraceptive use in diabetic women. Maturitas. 2009;63(1):128-150.

23. Janz N. Contraception in diabetic women: an Italian study. Diabetes Res Clin Pract. 2005;67(3):267-272.

24. Benotmane A, Faraoun K. Contraceptive practice in diabetic women in Algeria. Diabetes Metab. 2008;27(4):510-511.

25. Holing E. Why don't women with diabetes plan their pregnancies. Diabetes Care. 1998;21(6):889-895.

26. Vahratian A, Barber J, Lawrence J. Family planning practice among diabetes, over weight and obese women in 2002 national survey for family growth. Diabetes Care. 2009;32(6):1026-1031. 
International Journal of Women's Health

Dovepress

\section{Publish your work in this journal}

The International Journal of Women's Health is an international, peerreviewed open-access journal publishing original research, reports, editorials, reviews and commentaries on all aspects of women's healthcare including gynecology, obstetrics, and breast cancer. The manuscript management system is completely online and includes Visit http://www.dovepress.com/testimonials.php to read real quotes from published authors.

Submit your manuscript here: http://www.dovepress.com/international-journal-of-womens-health-journal 